Mark D. Agee* and Thomas D. Crocker

\title{
Are Current U.S. Anti-Bullying Programs Net Beneficial to Parents? Inferences from School Switching ${ }^{1}$
}

Abstract: This paper applies a discrete choice version of the household production framework to assess parents' ex ante willingness to pay to reduce their child's victimization from bullying at school. Willingness to pay is estimated using a bivariate probit model and a unique panel of 595 families from the NICHD Study of Early Child Care and Youth Development for 2000 to 2003. Empirical results find a statistically significant positive association between an elementary school child's bully victimization and parents' choice to change their child's school in the subsequent sample period. Parents' annual willingness to pay for reduced child bully victimization averages $\$ 130$ and ranges from $\$ 54$ for parents whose child was not bullied to $\$ 633$ for parents whose child was bullied. Given current literature estimates of U.S. bullying prevalence and the cost and effectiveness of currently available antibullying programs, parental willingness to pay estimates suggest that U.S. households' net annual return on investments in elementary school bullying prevention programs could be substantial.

Keywords: discrete choice models; household production; parental willingness to pay; school bullying prevention programs.

JEL classifications: C35; D13; J13.

\section{Introduction}

Children live in multiple environments: home, school, neighborhood, community and society. Within the interaction between children and these environments are risk factors for victimization from bullying. Bullying in the school setting has become a significant public health issue in the United States (Perkins, Perkins \& Craig, 2009). Public concern about the pervasiveness and harmful consequences of bullying in

1 Constructive comments from two anonymous referees are gratefully acknowledged.

*Corresponding author: Mark D. Agee, Department of Economics, Pennsylvania State University, Altoona, PA 16601, USA, e-mail: mda4@psu.edu

Thomas D. Crocker: Department of Economics and Finance, University of Wyoming, Laramie, WY 82071, USA, e-mail: tcrocker@uwyo.edu 
its schools has spanned the U.S. political spectrum (Puhl, Luedicke \& King, 2015). From 1999 to 2010, more than 120 anti-bullying bills were enacted by 46 U.S. state legislatures (U.S. Department of Education, 2011).

Bullying induces emotional and physical fear in students. A relentless threat of direct or indirect actions such as teasing, threatening to cause harm, intentional social exclusion, spreading rumors, or physical or verbal attacks pervades the lives of bullying victims. Student truancy and drop-out rates are higher in schools with higher bullying rates (Eriksen, Nielsen \& Simonsen, 2014). And although it is inherently difficult to assess the long-term human capital consequences of bullying separate from the effects of other genetic and environmental factors, an extensive multidisciplinary chronicle of evidence suggests that some of the emotional and/or physical damages from bullying can extend into adulthood. Bullying victims exhibit higher rates of unemployment and financial, mental, and physical health problems (Baldry, 2004; Arseneault et al., 2006; Arseneault, Bowes \& Shakoor, 2010; Brown \& Taylor, 2008; Wolke, Copeland, Angold \& Costello, 2013; Sarzosa \& Urzúa, 2015). This evidence suggests a tangible ex post human capital benefit of reducing children's exposure to bullying.

In addition to the conditional or unconditional altruism parents experience from their children's human capital formation, they may directly enjoy their own lives more when they can engage or participate in the lives of their children (Agee \& Crocker, 2011). From an economic perspective, the value of a public anti-bullying program partly depends on whether parents themselves value the program since they value their children's well-being. A program in which parents realize no personal value will obtain less political support. But we are unaware of any findings offering estimates of the value parents attach to reducing the risk their children will be victimized by bullies at school.

A well-established economic valuation literature (e.g., Agee \& Crocker, 2007; Dickie \& Gerking, 2007) shows that parents' ex ante preference-based values can be a significant component of the benefits of reducing environmental disamenities affecting children. Here our focus on school bullying suggests the analytical framework this literature embodies can monetize the benefits of a broad range of educational and social interventions to be set against program money costs. Also, our further focus on parental values takes account of the fact that children live in households. Household parents or caregivers make resource reallocations in response to changes in their children's environments. Overlooking behavioral reactions and the endogeneity of parental reactions to these changes will undervalue them (Pitt, Rosenzweig \& Hassan, 1990). Rarely does the noneconomic literature on educational and social interventions systematically recognize these issues.

In this paper, we apply a unique data set to a discrete choice version of the household production framework (Becker, 1965; Lancaster, 1966) to assess 
parents' ex ante preference-based value to reduce the risk of their child being bullied at school. We treat parents' ex ante perceived quality of their child's current school as conditional upon their child's exposure to bullying, school and family characteristics, and the child protection efforts parents choose to make. Parents' preference-based value is the monetary equivalent of the impact of the child's bully victimization on parents' discrete choice to change their child's school. Section 2 outlines a simple household production model, derives value expressions, and describes our estimation and identification strategies. Section 3 details the data and presents empirical results based on bivariate probit estimates of parents' conditional demand for a school change. Section 4 provides an illustrative comparison of parental values to the costs of several commonly used U.S. anti-bullying programs. Section 5 offers concluding remarks and some caveats.

\section{Model}

The household production framework (e.g., Becker, 1965; Lancaster, 1966 serves as the theoretical basis for deriving parents' ex ante willingness to pay for reduced own child bully victimization. This framework emphasizes that households combine market good purchases with time and other nonmarket inputs to produce commodities for final consumption. Applications often posit a cooperative agreement among adult household members about the utility function to be maximized subject to a full-income budget constraint determined by members' pooled resources (e.g., Scapecchi, 2005). Let parents' expected utility, $U(\cdot)$, be a quasiconcave, weakly separable function of consumption goods, $Z$, that directly affect utility, and their perceived quality, $Q$, of their child's schooling:

$$
U=U\left(Z, Q\left(Z, R, \alpha ; \gamma_{Q}\right) ; \gamma_{U}\right)
$$

where $U_{Z}>0$ and $U_{Q}>0$. The variable $Q$ measures on a real interval parents' perceptions of overall school quality. A subset of consumption goods, $Z$, (e.g., interactions with their child; location of the family home) can also affect $Q$. Perceived quality $Q(\cdot)$ is a concave, weakly separable function of parents' known attributes, $\alpha$, of their child's school (e.g., teacher qualifications, class composition, problems with bullying) and the set, $R$, of protection inputs, which affect parental utility indirectly by way of their direct impact on perceived school quality (e.g., seeking support and help from teachers or school administrators, moving the child to a new school). The vectors, $\gamma_{U}$ and $\gamma_{Q}$ denote exogenous or predetermined household and school attributes that may influence parents' preferences and/or their production or perceptions of school quality. 
Households face a full-income budget constraint written as:

$$
Y=q_{Z} Z+q_{R} R,
$$

where full prices are $q_{j}=\left(m_{j}+w \tau_{j}\right), j=Z, R$, and full income is $Y=$ $I+w\left(T-\tau_{L}\right) \cdot m_{j}$ is the money price of commodity $j ; w$ is the opportunity cost of parental time; $\tau_{j}$ is the time required to produce and/or consume one unit of commodity $j$; and $\tau_{L}$ is parental time spent away from work, including childcare time and personal leisure. Full income $Y$ is the sum of nonlabor income, $I$, and labor income, $w\left(T-\tau_{L}\right)$. Households allocate their time and market goods purchases to produce commodities, including perceived quality of child schooling, so as to maximize their joint utility function in (1) subject to their technology, $Q(\cdot)$, and time and income constraints embedded in (2). Children are presumed passive regarding parents' decisions.

If parents' perceptions of school quality can be influenced by their personal choices, the abovementioned model can be used to derive a preference-based value associated with an exogenous change in any perceived school attribute contained in $\alpha$. Given the assumed curvature properties of the school quality production function, $Q(\cdot)$, and household utility function in (1), parents' maximization of (1) subject to (2) yields their indirect utility function, $v(\cdot)$, which is continuous and strictly increasing in income, $Y . v(\cdot)$ can be inverted to find the expenditure function, $E(\cdot)$, which satisfies

$$
U=v(q, \alpha ; \gamma, E(q, \alpha ; \gamma, U)) .
$$

Denoting Victim $\in \alpha$ as an indicator of parents' awareness that their child is being bullied at school, their marginal valuation, $M V_{V i c t i m}$, of a reduction in child bullying is given by:

$$
M V_{\text {Victim }} \equiv \partial E / \partial \text { Victim }=-(1 / \lambda) \partial v(\cdot) / \partial \text { Victim },
$$

where $\lambda \equiv \partial v(\cdot) / \partial Y$ denotes the marginal utility of income. Expression (4) portrays parents' marginal disutility of bullying, converted to monetary units by way of the marginal utility of income. Expression (4) is empirically intractable because actual utility levels are not observed. However, a consensus branch of the valuation literature has shown $M V_{\text {Victim }}$ to be estimable using parents' conditional compensated demand for a remedial input linked to Victim (Freeman, Herriges $\&$ Kling, 2014). Herein, a discrete choice version of $M V_{\text {Victim }}$ is framed as the marginal impact of a child's risk of exposure to bullying upon parents' decision to change their child's school in a given period, conditional on family characteristics and attributes of the child's current school. Throughout, we assume the distribution of the child's school change opportunities to be independent of current school attributes, such as location and socioeconomic makeup which may help (e.g., busing) or hinder (e.g., exclusions) these opportunities. We thus consider only one of 
the two ways in which attributes of the child's current school can affect the parents' school change decision. That is, we account for the impact of the child's current school upon parental utility but set aside any impact upon school change opportunities.

Observation of discrete choices reflects individuals' optimization of "conditional" utility when their utility functions include a stochastic term comprised of personal tastes and/or tendencies unobserved by the investigator (e.g., McFadden, 1980). Small and Rosen (1981), Hau (1985), and others derive expressions for the ex ante utility-preserving tradeoff between money income and an exogenous increase (or decrease) in the price or quality of a particular activity, conditional on the individual's choice to engage the activity. Bockstael and McConnell (1983) examine this approach in the context of household production. Following these literature results, let

$$
v_{i t}=\bar{v}_{i t}(q, \text { Victim, } \gamma, Y)+\mu_{i t},
$$

define household $i$ 's conditional indirect utility, at time $t$, associated with changing their child's current school. As in McFadden (1974, 1976), conditional utility in (5) can be split into two components: $\bar{v}_{i t}(\cdot)$ represents the conditional benefit of a school change for the "average" parent; and $\mu_{i t}$ is a stochastic term encompassing unobserved family-specific influences and random factors that separate parent $i$ from the average. The vector $\gamma$ contains observable attributes of the family, the child, and the child's school. Assuming parents base their decision rule on utility maximization, outcome probabilities can be derived specifying parents' decision rules and a given distribution of utility levels (Hau, 1985). Denoting $\bar{v}_{1 i t}$ as parents' maximum attainable utility when a school change is chosen, and $\bar{v}_{0 i t}$ as maximum attainable utility when no change is chosen, parent $i$ at time $t$ will choose to change their child's school if $\bar{v}_{1 i t}>\bar{v}_{0 i t}$. The probability of a school change conditional on prices, income and observable characteristics, is

$$
\pi_{1 i t}=\operatorname{Pr}\left(\mu_{0 i t}-\mu_{1 i t}<\bar{v}_{1 i t}-\bar{v}_{0 i t}\right) .
$$

Following Small and Rosen (1981), if the compensated demand curve for a school change is approximated by its Marshallian counterpart, parents' $M V_{\text {Victim }}$ in expression (4) is

$$
M V_{\text {Victim }}=\left(\frac{\partial \bar{v}_{1 i t} / \partial \text { Victim }}{\partial \bar{v}_{1 i t} / \partial Y}\right) \pi_{1 i t} .
$$

Since the vast majority of sample families used in this study send their children to public school, following Willig (1976), tuition and fees for child schooling are small enough (see Table 1) to assume a reasonable compensated-Marshallian approximation. 
Table 1 Variable names, definitions, and descriptive statistics $(N=1785)$.

\begin{tabular}{|c|c|c|c|c|}
\hline \multirow{3}{*}{ Variable } & \multirow{3}{*}{ Definition } & \multicolumn{3}{|c|}{ Mean (Standard Deviation) } \\
\hline & & \multicolumn{3}{|c|}{ Year } \\
\hline & & 2000 & 2002 & 2003 \\
\hline \multicolumn{5}{|c|}{ Endogenous variables } \\
\hline Changed school & $\begin{array}{l}\text { Subject child changed schools during or } \\
\text { after the indicated year for reasons other } \\
\text { than grade promotion; } 1=\text { yes, } 0=\text { no. }\end{array}$ & $\begin{array}{l}0.0515 \\
(0.221)\end{array}$ & $\begin{array}{r}0.04 \\
(0.181)\end{array}$ & $\begin{array}{r}0.034 \\
(0.177)\end{array}$ \\
\hline Victim & $\begin{array}{l}\text { Subject child scored at least one stan- } \\
\text { dard deviation above the sample mean } \\
\text { in the indicated year on the KMCS vic- } \\
\text { timization survey; } 1=\text { yes, } 0=\text { no. }\end{array}$ & $\begin{array}{r}0.13 \\
(0.34)\end{array}$ & $\begin{array}{r}0.14 \\
(0.35)\end{array}$ & $\begin{array}{r}0.17 \\
(0.37)\end{array}$ \\
\hline \multicolumn{5}{|l|}{ Parent Variables } \\
\hline Dad education & Father's education in years completed. & $\begin{array}{l}14.66 \\
(2.66)\end{array}$ & & \\
\hline Dad home & $\begin{array}{l}\text { Subject child's father lives } \\
\text { at home; } 1=\text { yes, } 0=\text { no. }\end{array}$ & $\begin{array}{r}0.705 \\
(0.456)\end{array}$ & $\begin{array}{r}0.68 \\
(0.467)\end{array}$ & $\begin{array}{r}0.681 \\
(0.466)\end{array}$ \\
\hline Income & $\begin{array}{l}\text { Total annual household income in } \\
1000 \text { s of nominal dollars. }\end{array}$ & $\begin{array}{l}75.666 \\
(64.52)\end{array}$ & $\begin{array}{l}84.641 \\
(75.48)\end{array}$ & $\begin{array}{r}86.777 \\
(79.14)\end{array}$ \\
\hline Mom age at birth & $\begin{array}{l}\text { Mother's age in years at the birth of } \\
\text { the subject child. }\end{array}$ & $\begin{array}{l}28.56 \\
(5.58)\end{array}$ & & \\
\hline Mom education & Mother's education in years completed. & $\begin{array}{r}14.42 \\
(2.4)\end{array}$ & & \\
\hline Number of children & $\begin{array}{l}\text { Total number of children under } 18 \\
\text { residing in the subject child's home. }\end{array}$ & $\begin{array}{r}2.4 \\
(0.97)\end{array}$ & $\begin{array}{r}2.46 \\
(1.03)\end{array}$ & $\begin{array}{r}2.44 \\
(1.04)\end{array}$ \\
\hline School cost & $\begin{array}{l}\text { Annual tuition and fees of the sub- } \\
\text { ject child's school in } 1000 \text { s of nom- } \\
\text { inal dollars. }\end{array}$ & $\begin{array}{r}0.468 \\
(1.393)\end{array}$ & $\begin{array}{r}0.529 \\
(1.747)\end{array}$ & $\begin{array}{l}0.568 \\
(1.83)\end{array}$ \\
\hline \multicolumn{5}{|l|}{ Child variables } \\
\hline$A D H D$ & $\begin{array}{l}\text { Subject child has an attention and/or } \\
\text { hyperactivity disorder; } 1=\text { yes, } 0=\text { no. }\end{array}$ & $\begin{array}{r}0.087 \\
(0.281)\end{array}$ & $\begin{array}{r}0.102 \\
(0.303)\end{array}$ & $\begin{array}{r}0.070 \\
(0.255)\end{array}$ \\
\hline Birth order & Subject child's birth order. & $\begin{array}{r}1.80 \\
(0.91)\end{array}$ & & \\
\hline Boy & Subject child is male; $1=$ yes, $0=$ no. & $\begin{array}{r}0.507 \\
(0.5)\end{array}$ & & \\
\hline Child age & Subject child's age in years. & $\begin{array}{r}8.43 \\
(0.36)\end{array}$ & $\begin{array}{l}10.43 \\
(0.36)\end{array}$ & $\begin{array}{l}11.43 \\
(0.36)\end{array}$ \\
\hline
\end{tabular}


Table 1 (continued)

\begin{tabular}{|c|c|c|c|c|}
\hline \multirow{3}{*}{ Variable } & \multirow{3}{*}{ Definition } & \multicolumn{3}{|c|}{ Mean (Standard Deviation) } \\
\hline & & \multicolumn{3}{|c|}{ Year } \\
\hline & & 2000 & 2002 & 2003 \\
\hline \multirow[t]{2}{*}{ Child height } & Subject child's height-for-age & 0.258 & 0.439 & 0.449 \\
\hline & z-score in the indicated year. & $(0.956)$ & $(0.981)$ & $(0.992)$ \\
\hline \multirow[t]{2}{*}{ Prosocial behavior } & Subject child's total raw score on the & 1.66 & 1.659 & 1.663 \\
\hline & SSRS prosocial behavior subscale. & $(0.367)$ & $(0.361)$ & $(0.36)$ \\
\hline \multirow[t]{2}{*}{ Nonwhite } & Subject child is nonwhite; & 0.19 & & \\
\hline & $1=$ yes, $0=$ no & $(0.398)$ & & \\
\hline \multicolumn{5}{|l|}{ School variables } \\
\hline \multirow[t]{2}{*}{ Principal age } & Principal's age in years & 49.95 & 50.16 & 50.83 \\
\hline & (principal questionnaire). & $(7.23)$ & $(8.14)$ & (6.16) \\
\hline \multirow[t]{2}{*}{ School delinquencies } & Number of reported student delinquency & 3.07 & 3.19 & 6.41 \\
\hline & $\begin{array}{l}\text { problems at the subject child's school in } \\
\text { the indicated year (principal question- } \\
\text { naire). }\end{array}$ & $(0.41)$ & $(0.68)$ & $(1.49)$ \\
\hline \multirow[t]{2}{*}{ Teacher education } & Subject child's teacher's edu- & 16.928 & 16.93 & 16.98 \\
\hline & cation in years completed. & $(1.03)$ & $(1.02)$ & $(1.06)$ \\
\hline \multirow[t]{2}{*}{ Teacher support } & Teacher indicated (on the teacher ques- & 0.54 & 0.55 & 0.65 \\
\hline & $\begin{array}{l}\text { tionnaire) at least good administrative } \\
\text { support for teaching quality; } 1=\text { yes; } \\
0=\text { no. }\end{array}$ & $(0.136)$ & $(0.141)$ & $(0.139)$ \\
\hline
\end{tabular}

Expression (7) complicates welfare measurement because parents' choice of a school change for their child represents only one of plausibly several remedial actions available to parents to reduce their child's exposure to bullying (e.g., seeking help from teachers). Bockstael and McConnell (1983) showed in a general context that if positive parental benefits associated with reduced bullying exist even when a school change is not chosen, $M V_{V i c t i m}$ in (7) will underestimate the true $M V_{\text {Victim }}$. Thus, while some parents might find their bullied child's current school unacceptable, other parents might opt for remedial actions whilst keeping their child's current school or simply doing nothing. As a consequence, the empirical value estimates reported below are interpreted as a lower bound on parents' true willingness to pay to reduce their child's bully victimization. 


\section{Empirical specification}

To specify the binary choice model for a school change, let parents' conditional indirect utility function in (5) be expressed as a linear combination of observable variables:

$$
v_{1 t}=\beta_{0}+\beta_{V} \operatorname{Victim}_{i t}+\sum_{k=1}^{K} \beta_{k} \gamma_{k i t}+\lambda\left(\text { Income }_{i t}-\text { School Cost }_{i t}\right)+\mu_{i t},
$$

where $\lambda$ and $\beta_{V}$, respectively, are interpreted as the conditional marginal utilities of income and bully victimization. The variable Victim enters (8) as a binary indicator of the child's exposure to bullying, and is assumed endogenous according to:

$$
\operatorname{Victim}_{i t}^{*}=\delta_{0}+\sum_{h=1}^{H} \delta_{h} X_{h i t}+\omega_{i t},
$$

where Victim ${ }_{i t}^{*}$ is a latent indicator of child $i$ 's victimization from bullying at time $t$, whereby $\operatorname{Victim}_{i t}=1$ if Victim ${ }_{i t}^{*}>0$, and $X_{h i t}$ is the $h$ th exogenous or predetermined explanatory variable related to being bullied. As discussed further below, some or all of the explanatory variables in (8) may or may not enter $X_{h i t}$ in (9) depending on exclusion restrictions. Assuming the error terms $\mu_{i t}$ and $\omega_{i t}$ are distributed bivariate normal with mean zero, constant variance, and $\operatorname{corr}\left(\mu_{i t}, \omega_{i t}\right)=\rho$, consistent estimates of (8) and (9) can be obtained using a recursive bivariate probit model. If $\rho=0$, Victim $_{i t}$ and $\mu_{i t}$ are uncorrelated implying Victim $i t$ in expression (8) is exogenous.

Inattention to $\rho \neq 0$ may confound an estimate of the marginal effect of (9) upon (8) with unobserved parent, child, and school variables correlated with observed variables. Bhattacharya, Goldman and McCaffrey (2006) used Monte Carlo simulations to compare the performance of various estimators commonly used to estimate the effect of a binary treatment variable upon a binary outcome variable. They found the bivariate probit model performed best for generating consistent estimates of the marginal treatment effect. The recursive structure of the bivariate probit model builds on the reduced form equation (9) for the posited endogenous dummy variable, Victim, which then enters the structural form equation (8) determining parents' conditional benefit of changing their child's school. This model belongs to a general class of simultaneous equation models with discrete endogenous variables introduced by Heckman (1978). Heckman stated in his more general context that full rank of the regressor matrix is sufficient for the identification of all model parameters; however, Maddala (1986) argued that some variables contained in the reduced form equation must be excluded from the structural equation in order to produce consistent estimates. Wilde (2000) showed that 
identification is indeed achieved as soon as both equations of the model contain a varying exogenous regressor. While Wilde's result, commonly referred to as "identification by function form," does not require availability of additional instruments in the reduced form equation, it is valid only in the context of a bivariate normal distribution. Thus, in the absence of additional instruments, identification relies heavily on the assumption of bivariate normality. Since bivariate normality may be a strong assumption, exclusion restrictions help in making estimation results more robust to distributional misspecification (Jones, 2007), including exogeneity tests (Monfardini \& Radice, 2008). As a result, Table 2 reports bivariate probit estimates of expressions (8) and (9) with and without exclusion restrictions.

\section{Data and empirical implementation}

Data for this study come from the National Institute of Child Health and Human Development Study of Early Child Care and Youth Development (NICHDSECCYD, 2001), a longitudinal study of the linkages between child behavior and development, particularly as it relates to early child care, schooling, and after school care. Families were recruited shortly after the birth of the subject child in 1991 from 10 geographically dispersed areas of the United States, both urban and rural, and data were collected prospectively from birth to age 15 . All sample children had a mother who was over 18 at the time of birth, had no disabilities or health conditions requiring a hospital stay exceeding 7 days postpartum, and lived in a home where English was the first language. In addition, all respondent families affirmed no future plans of moving from their current residence location. Details of the recruitment methods and sampling strategy are available at U.S. Department of Health and Human Services (2010). The initial sample included 1,364 children, very few of whom shared the same school. Although the sample is not nationally representative, it is representative of the demographics of the 10 areas from which the sample was recruited. The NICHD data includes extensive information about parenting, marriage, employment, income, and participation in public programs, as well as other relevant topics, such as detailed assessments of children's health and scholastic abilities, social and behavioral attributes, and qualities of their home, school, and after school environments.

The present analysis uses data from phase 3 of the NICHD study, which followed sample children from grades two through six. The phase 3 data measures two variables relevant to the current study. First, at the end of each school year, at least one respondent parent or primary caregiver completed a questionnaire regarding attributes of their child's schooling and, if any, after school care. In Table 1, 
Table 2 Binary and bivariate probit estimates ${ }^{\mathrm{a}}$.

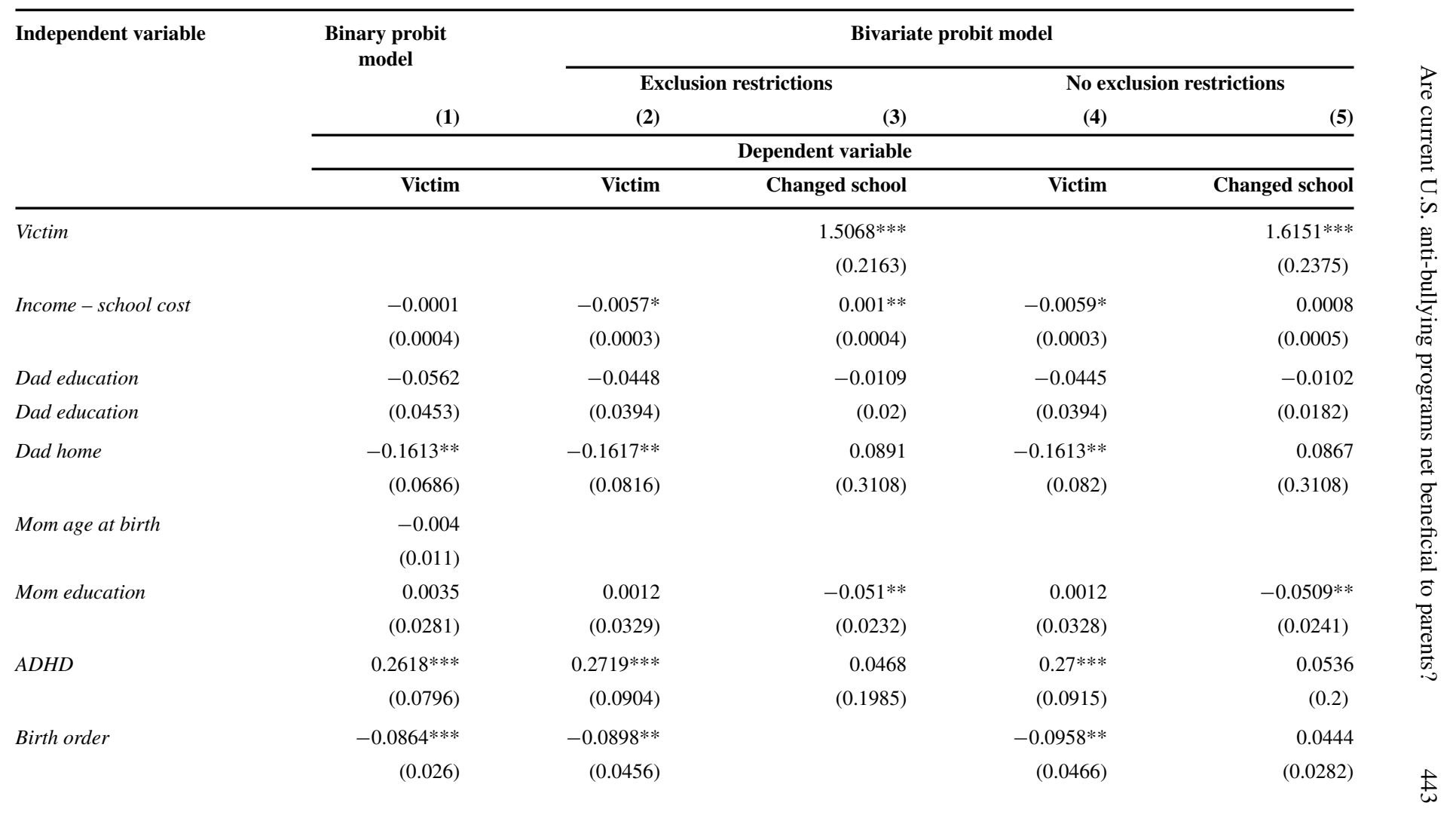


Table 2 (continued)

\begin{tabular}{|c|c|c|c|c|c|}
\hline \multirow[t]{5}{*}{ Independent variable } & \multirow{3}{*}{$\begin{array}{l}\text { Binary probit } \\
\text { model } \\
\\
\end{array}$} & \multicolumn{4}{|c|}{ Bivariate probit model } \\
\hline & & \multicolumn{2}{|c|}{ Exclusion restrictions } & \multicolumn{2}{|c|}{ No exclusion restrictions } \\
\hline & & (2) & (3) & (4) & $(5)$ \\
\hline & \multicolumn{5}{|c|}{ Dependent variable } \\
\hline & Victim & Victim & Changed school & Victim & Changed schoo \\
\hline \multirow[t]{2}{*}{ Boy } & 0.0083 & -0.009 & $0.1646^{* *}$ & -0.0091 & $0.167^{* *}$ \\
\hline & $(0.01)$ & $(0.1001)$ & $(0.0694)$ & $(0.1003)$ & $(0.0717)$ \\
\hline \multirow[t]{2}{*}{ Child height } & -0.0292 & & & & \\
\hline & $(0.0289)$ & & & & \\
\hline \multirow[t]{2}{*}{ Prosocial behavior } & $-0.0664 * * *$ & $-0.0627^{* * *}$ & & $-0.0635^{* * *}$ & 0.009 \\
\hline & (0.0118) & $(0.0121)$ & & $(0.0133)$ & $(0.0155)$ \\
\hline \multirow[t]{2}{*}{ Nonwhite } & -0.077 & -0.0631 & 0.0793 & -0.0641 & 0.0774 \\
\hline & $(0.0524)$ & $(0.0491)$ & $(0.15)$ & $(0.0516)$ & $(0.1592)$ \\
\hline \multirow[t]{2}{*}{ Principal age } & $-0.0042 * *$ & $-0.0044 * *$ & & $-0.0042 * *$ & -0.0024 \\
\hline & $(0.0021)$ & $(0.0021)$ & & $(0.002)$ & $(0.0049)$ \\
\hline \multirow[t]{2}{*}{ School delinquencies } & $0.059 * * *$ & $0.0525 * *$ & -0.0144 & $0.0525 * *$ & -0.0195 \\
\hline & $(0.0193)$ & $(0.0233)$ & $(0.061)$ & $(0.0233)$ & $(0.0587)$ \\
\hline \multirow[t]{2}{*}{ Teacher education } & $-0.0132 * * *$ & $-0.0135^{* * *}$ & 0.0031 & $-0.0136 * * *$ & 0.003 \\
\hline & $(0.003)$ & $(0.0037)$ & $(0.0061)$ & $(0.0037)$ & $(0.006)$ \\
\hline
\end{tabular}


Table 2 (continued)

\begin{tabular}{|c|c|c|c|c|c|}
\hline \multirow[t]{5}{*}{ Independent variable } & \multirow{3}{*}{$\begin{array}{l}\text { Binary probit } \\
\text { model } \\
\\
\end{array}$} & \multicolumn{4}{|c|}{ Bivariate probit model } \\
\hline & & \multicolumn{2}{|c|}{ Exclusion restrictions } & \multicolumn{2}{|c|}{ No exclusion restrictions } \\
\hline & & (2) & (3) & (4) & (5) \\
\hline & \multicolumn{5}{|c|}{ Dependent variable } \\
\hline & Victim & Victim & Changed school & Victim & Changed school \\
\hline \multirow[t]{2}{*}{ Teacher support } & $-0.0088 * * *$ & $-0.0069 * * *$ & $-0.0142 * *$ & $-0.0069 * * *$ & $-0.0138 * *$ \\
\hline & $(0.0024)$ & $(0.0022)$ & $(0.0073)$ & $(0.0021)$ & $(0.007)$ \\
\hline \multirow[t]{2}{*}{ Grade 5 dummy } & 0.0889 & 0.0617 & -0.1799 & 0.0613 & -0.177 \\
\hline & $(0.1301)$ & $(0.121)$ & $(0.1515)$ & $(0.1215)$ & $(0.154)$ \\
\hline \multirow[t]{2}{*}{ Grade 6 dummy } & 0.0133 & 0.0329 & -0.0957 & 0.0343 & -0.0785 \\
\hline & $(0.1656)$ & $(0.1704)$ & $(0.2273)$ & $(0.1683)$ & $(0.2145)$ \\
\hline \multirow[t]{2}{*}{ Constant } & 0.5666 & 0.3748 & $-1.1255^{* * *}$ & 0.3796 & $-1.225^{* * *}$ \\
\hline & $(0.487)$ & $(0.5059)$ & $(0.4241)$ & $(0.5324)$ & $(0.4345)$ \\
\hline Number of observations & 1785 & \multicolumn{2}{|c|}{1785} & \multicolumn{2}{|c|}{1785} \\
\hline Chi-square & $68.78 * *$ & \multicolumn{2}{|c|}{$156.96 * *$} & \multicolumn{2}{|c|}{$183.53 * *$} \\
\hline Estimated correlation $(\rho)$ & & \multicolumn{2}{|c|}{-0.652} & \multicolumn{2}{|c|}{-0.687} \\
\hline LR $\chi^{2}$ test of $H_{0}: \rho=0$ & & \multicolumn{2}{|c|}{$40.67 * * *$} & \multicolumn{2}{|c|}{$30.65 * * *$} \\
\hline
\end{tabular}

${ }^{\mathrm{a}}$ Robust standard errors in parentheses.

Note: Significant at: *** less than $1 \%$; ** less than $5 \% ; *$ less than $10 \%$. 
the dichotomous variable Changed School equals one if the respondent parent moved their child to a different school during the indicated (Table 1) year, or planned a school change the following year for reasons other than ordinary grade progression. Table 1 shows that approximately $4 \%-5 \%$ of sample parents changed their child's school in either third, fifth, or sixth grades.

Unique to the phase 3 data is the subsample of 895 children who completed (with at least one parent/caregiver present) a detailed questionnaire intended to measure each child's degree of victimization from bullying at their current school. The questionnaire was given to children on three separate occasions: grade 3 (children approximately age 9), grade 5 (age 11), and grade 6 (age 12). Children's selfreported victimization from bullying was measured using the Kids in My Class at School questionnaire (U.S. Department of Health and Human Services, 2010). Created specifically for use in the SECCYD, the Kids questionnaire was adapted from an instrument developed by Ladd, Kochenderfer and Coleman (1997) to study the impact of bullying victimization upon various measures of children's elementary school adjustment. Levels of bully victimization measured by the Kids questionnaire have been found to be comparable to levels measured by the more widely used Olweus Bullying Survey (Kochenderfer \& Ladd, 1996, 1997; Henrich \& Shahar, 2014). Respondent children were asked to choose a number from 1 to 5 (never; hardly ever; sometimes; most of the time; and always). The questionnaire asked children to consider the extent to which they experienced peer bullying or aggression in their class or around school using the following questions: Does anyone in your class ever: (1) pick on you at school; (2) say mean things to you at school; (3) say bad things about you to other kids at school; and/or (4) hit you at school? An overall bullying victim score was then calculated as the sum of the four items (Cronbach's alpha $=0.76-0.85$ across the three waves indicating good internal reliability). In accordance with previous studies utilizing NICHD bullying victim data (e.g., Fanti \& Georgiou, 2013; Fanti, Frick \& Georgiou, 2009), this study measures child bully victimization using the constructed binary variable, Victim, which equals one in the indicated year if a sample child's questionnaire score was at least one standard deviation above the sample mean, and zero otherwise. Based on this classification method, Table 1 shows that approximately $13 \%$ of sample children were victims of bullying in grade 3,14\% were victims in grade 5, and $17 \%$ were victims in grade 6 . These rates are comparable to the $15 \%-20 \%$ U.S. prevalence rate reported by the U.S. Department of Education (NCES, 2014), and by Cook, Williams, Guerra, Kim and Sadek (2010).

Table 1 presents definitions, means, and standard deviations of all covariates used to estimate expressions (8) and (9). Our sample consists of 1,785 observations on the 595 children and families having no missing data for the years 2000, 2002, 
and 2003. In comparison to the 2003 average U.S. household, the average sample household in Table 1 is more educated (mother's and father's education is approximately 14.25 years vs. the U.S. average of 12.7$)$ and earns more income $(\$ 77,000$ vs. the U.S. average of $\$ 51,750$ ), but differs only slightly according to ethnicity (12.9\% African American vs. 12.5\% U.S., and 6.1\% Hispanic vs. 9.1\% U.S.).

Variables identified in the literature as important determinants of a child's risk of being bullied guide the specification of Victim in expression (9). While any child can be the victim of bullying, children who are different, either socially or physically, from their peers are more likely to be victimized. Children who are in the ethnic minority in a school are more likely to be bullied (Graham, 2006). Children with special needs are also disproportionately victims of bullying. In particular, children with attention or hyperactivity disorders often report that they are bullied as a result of their disorder (Rose, Allison \& Simpson, 2012). Children with other different physical characteristics may be victimized, such as being overweight or underweight, short or tall, wear their hair differently, wear different clothing, wear glasses, or come from a different socioeconomic background (Cook et al., 2010; Duncan, 2011; Due, Merlo, Harel-Fisch, Trab Damsgaard \& Holstein, 2009). In contrast, children who exhibit prosocial behavior (e.g., nonaggressive assertiveness, increased interaction, and conflict resolution skills) are at significantly lower risk of being bullied (Schwartz, Dodge \& Coie, 1993; Egan \& Perry, 1998; Eisenberg, Fabes \& Spinrad, 2006). School characteristics also play a major role. Bullying problems proliferate in unsafe and/or unsupportive school environments (Kasen, Johnson, Chen, Crawford \& Cohen, 2011). One of the strongest predictors of bullying victimization is some form of delinquency occurring on or near school grounds, such as vandalism, carrying of weapons, or gang activity (Swearer et al., 2006). Other school characteristics associated with higher bullying rates include understaffed and less academically engaged classrooms, inexperienced teachers and administrators, and inadequate financial support or administrative leadership for teachers (Smedley \& Willower, 1981; Short, 1988; Tirozzi, 2001; Nansel, Haynie \& Simonsmorton, 2003; Doll, Song \& Siemers, 2004; Holt \& Keyes, 2004).

Parent and child variables entering expression (9) include parent education, income, household composition and ethnicity (identical to child ethnicity), the mother's age at the birth of the subject child, the subject child's birth order, heightfor-age z-score (indicating relative stature), and gender. Since no sample household changed residence, children's schooling was mandatory, and schooling options were nearly all public (and thus similar in cost), we use residual income (annual income minus annual school cost) as our income measure. Also entering expression (9) is a dummy variable indicating whether the subject child was diagnosed with an attention or hyperactivity disorder $(A D H D)$, and the child's total raw score on 
the Social Skills Rating System prosocial behavior subscale (Prosocial Behavior). The prosocial behavior subscale assesses multiple elements of a child's general social skills in and out of school (Gresham \& Elliott, 1990). In Table 1, the Prosocial Behavior total raw score is the arithmetic mean of parents' and teachers' Likert scale responses about their observations of each child's peer and group interactions, problem-solving/decision-making, self-management, communication, cooperation, and assertiveness. The Social Skills Rating System subscale factors for prosocial behavior have been found to be stable over early and middle childhood developmental stages among elementary school children in longitudinal studies (Diperna $\&$ Volpe, 2005).

Variables used in expression (9) to characterize the subject child's school include School Delinquencies, the number of student-related delinquencies in the indicated year reported by the school principal (from the NICHD principle questionnaire); Principal Age, a proxy for administrative experience; years of Teacher Education; and Teacher Support, a dummy variable indicating whether the subject child's teacher (based on NICHD teacher survey responses) acknowledged at least "good" administrative support for teaching quality in the indicated year.

\section{Empirical Results}

Preliminary binary probit estimates of the probability of Victim are reported in column 1 of Table 2. Results indicate that subject children who reside in households with a father present, have a higher birth order (possibly the result of increased sibling socialization as in Hay, Payne \& Chadwick, 2004, and Swearer, Song, Cary, Eagle \& Mickelson, 2001), and greater parent- and teacher-observed prosocial behavior are less likely to be bullied at school. Also less likely to be bullied are children who attend schools staffed with older principals and more educated teachers who acknowledge good or better administrative support for quality teaching. In agreement with the literature, children with attention and/or hyperactivity disorders are more likely to be bullied as are children who attend schools with student delinquency problems. Parental income and education, and mother's age at birth, as well as child ethnicity, gender, stature, or grade level do not emerge as statistically significant influences on children's likelihood of bully victimization. Victimization probabilities are assumed independent across grades.

Columns $2-5$ in Table 2 report results from estimating two bivariate probit specifications of structural expressions (8) and (9). Both specifications exclude Mom Age at Birth and Child Height as these variables produced collinearity problems and were likewise individually and jointly insignificant in all specifications 
estimated. At the bottoms of columns $2-5$, likelihood ratio (LR) $\chi^{2}$ test statistics reject with $p$ values less than 0.01 the null hypothesis of $\rho=0$ (Victim is exogenous), where $\rho$ is the coefficient of correlation between the residuals from expressions (8) and (9). Monfardini and Radice (2008) found the LR test of $\rho=0$ performed better than Lagrange multiplier and conditional moment tests. Both models have a negative estimated residual correlation, suggesting that unobservable factors which decrease the probability of Victim also decrease the probability of Changed School.

We employ the exogenous or predetermined covariates Birth Order, Principal Age, and Prosocial Behavior as instruments to identify the single endogenous treatment covariate, Victim, in expression (8). Birth Order and Principal Age have no clearly compelling influence upon a parent's decision to change a child's school. As for the exclusion of Prosocial Behavior, since longitudinal studies of children's assessed social skills using the Social Skills Rating System are stable over early to middle childhood, a time-varying school change will not affect a child's Prosocial Behavior. The attribute likely therefore plays no direct role in a parent's school change decision.

Statistical inference also supports the logic of the abovementioned exclusion restrictions. First, the reduced form results reported in the first column of Table 2 suggest the variations of these instruments in these data make them credible identifiers. Neither do these instruments appear weak. As Chernozhukov and Hansen (2008) point out, because reduced form estimates are proportional to whatever causal effects are of interest, the statistical significance of these reduced form estimates for the instruments should be high if they are strong. They are high in Table 2. Staiger and Stock (1997) propose a rule-of-thumb first-stage F-statistic of at least 10.0 from the OLS regression of a single endogenous variable for an instrument set to qualify as strong. Here, an OLS regression of Victim on our instrument set yields an F-statistic of 29.3, implying that our instrument set is not weak.

Finally, we cannot unequivocally rule out the possibility that our instruments directly affect the School Change outcome as well as the Victim treatment. Nor can we deny the chance they are systematically related to unobservables such as student groupings and their norms. Yet if either of these possibilities holds, the common parameter estimates for School Change in columns 3 and 5 of Table 2 should vary suggestively with inclusion or exclusion of the instrument set. Here this inclusion or exclusion generates no clearly suggestive differences. The signs for all common School Change coefficients in columns 3 and 5 are identical and only Income - School Cost, School Delinquencies, and the Grade 6 dummy variable display any appreciable difference in magnitude and statistical significance between these columns. Nevertheless, the difference between the restricted and the unrestricted 
estimates for each of these variables is only a tiny fraction of their standard errors. We conclude that our instruments drive Victim, the treatment variable but not School Change, the outcome variable. These empirical counters to weak identification and unobserved heterogeneity make us comfortable in relying on standard methods of statistical inference using the estimated coefficients and standard errors.

Results in Table 2 columns 2-5 indicate that parents' knowledge of their child's victimization from bullying is positively associated with their probability of changing schools. Household income net of any school cost is also positively associated with school change probability. Families with more educated mothers are less likely to change schools. Male children are more likely to change. Children less likely to change schools are those studying in schools where teachers obtain more administrative support for their teaching. Estimated coefficients from both bivariate probit specifications exhibit similar signs and magnitudes with a few exceptions. In the unrestricted model, the positive association between Changed School and Income - School Cost is slightly weaker. The unrestricted model in column 5 indicates that Birth Order, Prosocial Behavior, and Principal Age impart no statistically significant influence. Finally, several specifications not reported in Table 2 were estimated containing multiple combinations of interactions among model covariates. In particular, Victim and Income - School Cost were interacted with Child Age and/or Grade dummies to investigate any time-varying relationships between these variables and parents' choice to change schools. No statistically significant time interactions emerged nor were there any significant interactions between parent, child, and school variables.

Using the model with exclusion restrictions in Table 2 columns 2-3 as the basis for value calculations, Table 3 reports mean estimates and $95 \%$ confidence intervals of sample parents' probability of a school change together with their annual marginal valuations of reduced bully victimization, $M V_{\text {Victim }}$. Table 3 values are calculated in accordance with expression (7): the direct product of the fitted probability of Changed School (for the indicated sample) and the ratio of estimated coefficients for Victim and Income - School Cost. Row 1 of Table 3 reports overall sample mean estimates. Rows 2-3 report estimates for subsamples of parents whose child was bullied and not bullied, and rows 4-6 report subsample estimates by household income. As earlier mentioned, estimated $M V_{\text {Victim }}$ constitutes a lower bound on the true value if Changed School is a nonessential input for the production of reduced bully victimization (Bockstael \& McConnell, 1983). Since the essential input criterion cannot be guaranteed here, Table 3 figures are interpreted as lower bound estimates, expressed in 2003 dollars, of parents' preference-based annual value to save one elementary school child from being bullied. In Table 3 , the average sample parent is willing to pay $\$ 137$ annually for a one-victim reduction. 
Table 3 Parental willingness to pay for reduced bullying ${ }^{\mathrm{a}}$.

\begin{tabular}{lrrr}
\hline & $\begin{array}{c}\text { Probability of } \\
\text { parents choosing } \\
\text { a school change }\end{array}$ & $\begin{array}{c}\text { Parental willingness } \\
\text { to pay for reduced } \\
\text { bully victimization } \\
\left(\boldsymbol{M} \boldsymbol{V}_{\text {Victim }}\right)\end{array}$ & $\begin{array}{c}\text { 95\% confidence } \\
\text { interval } \\
\text { (lower-upper) }\end{array}$ \\
\hline Overall sample mean & 0.075 & $\$ 130$ & $\$ 120-\$ 140$ \\
& 0.3598 & $\$ 633$ & $\$ 614-\$ 652$ \\
$\begin{array}{l}\text { Mean for parents whose } \\
\text { child was bullied }\end{array}$ & $(0.086)$ & $\$ 54$ & $\$ 52-\$ 56$ \\
$\begin{array}{l}\text { Mean for parents whose } \\
\text { child was not bullied }\end{array}$ & 0.0305 & $\$ 170$ & $\$ 150-\$ 189$ \\
$\begin{array}{l}\text { Mean for parents with } \\
\text { annual household income } \\
\text { less than } \$ 55,000\end{array}$ & $(0.018)$ & & \\
$\begin{array}{l}\text { Mean for parents with } \\
\text { annual household income } \\
\text { greater than } \$ 55,000 \text { but } \\
\text { less than } \$ 90,000\end{array}$ & 0.10 & $\$ 130$ & $\$ 115-\$ 150$ \\
$\begin{array}{l}\text { Mean for parents with } \\
\text { annual household income } \\
\text { greater than } \$ 90,000\end{array}$ & $0.139)$ & & \\
\hline
\end{tabular}

a 2003 dollars; figures are rounded to the nearest dollar.

${ }^{\mathrm{b}}$ Standard errors are in parentheses.

Source: Washington, DC: National Education Association (2003).

Sample parents of a child who was not bullied are willing to pay $\$ 55$ each year; parents of a bullied child are willing to pay $\$ 664$. Parental marginal valuations vary inversely with household income. This is due to the combined effect of a constant marginal utility of income and the negative estimated impact of Income - School Cost on the probability of Victim evident in column 2 (and 4) of Table 2.

\section{Benefits and costs of bullying prevention programs in U.S. schools}

Although Table 3 benefit estimates likely understate parents' true marginal willingness to pay to reduce bully victimization, they nonetheless suggest that U.S. households' net return on investments in elementary and middle school bullying prevention programs could be substantial. This idea can be illustrated using a 
simple benefit-cost framework combined with some consensus literature estimates of key parameters. Suppose an elementary school with student population, $p$, adopts a bullying prevention program with total cost, $p \times c$, where $c$ denotes program cost per student. Given the school's current rate of bullying, $b$, the school has a total of $p \times b$ student victims. If the program has success rate, $s$, defined as the fraction of total student victims reduced, then, by adopting the program, the school will save $p \times b \times s$ students from bullying.

As for the monetary benefit, since the bullying prevention program creates a school-wide public good (reduced victimization risk) which is nonexcludable and nondepletable, the aggregate marginal value of the public good equals the sum of marginal values of each of the affected individuals within the population (Johansson, 1991; Freeman et al., 2014). In parental value terms (and using earlier notation), the aggregate benefit of preventing one student bullying victim within the elementary school is approximately $p \times \overline{M V}_{\text {Victim }}$, where $\overline{M V}_{\text {Victim }}$ is the marginal value of the average parent. Multiplying the aggregate parental benefit by the number of student victims saved and differencing this product by total program cost (and extracting like terms) yields parents' total net benefit $(N B)$ of the school's bullying prevention program:

$$
N B=p\left[(p b s) \overline{M V}_{V i c t i m}-c\right],
$$

where the difference in square brackets represents net benefit per student. Expression (10) says the bullying prevention program is more likely to be net beneficial if: the school's parents attach a higher value to reduced bullying; the program is more successful $(s)$; the school's bullying problem is worse $(b)$; or the program's per student cost is lower $(c)$.

Expression (10) serves as a basis for evaluating some of the more researched and utilized bullying prevention programs in the United States. One of these is the Olweus Bullying Prevention Program (OBPP). To date, the OBPP has been implemented in several hundred U.S. schools and around the world (Olweus \& Limber, 2007). The OBPP has been associated with reductions in bullying behavior as well as decreases in student reports of general antisocial behavior, such as school vandalism, fighting, theft, and truancy (Limber, 2011). While OBPP cost data vary somewhat by region, grade level, and school size, according to Olweus.org (OBPP, 2015), for an elementary school with enrollment of 500 students (an enrollment close to the U.S. average; NCES, 2013), the total OBPP annual cost for materials, training, and other outlays (all figures hereafter expressed in 2003 dollars) is approximately $\$ 12,500$, or $\$ 25$ per student. Persson and Svensson (2013) noted that this figure excludes the program's indirect costs in the form of lost resources due to teacher and staff hours being used for program implementation. Since U.S. data on indirect costs of the OBPP are unavailable, based on Persson and Svensson 
(2013), we assume a total OBPP annual cost range of $\$ 12,500-\$ 75,000$ ( $\$ 25-\$ 150$ per student) for a 500-student U.S. elementary school. We interpret this range as a lower bound estimate of the annual cost of implementing the OBPP. This range is large enough to encompass the costs of other bullying prevention programs found to be effective in U.S. elementary schools, including Al's Pals (Lynch, Geller \& Schmidt, 2004), Second Step (Cooke et al., 2007), and Steps to Respect (Brown, Low, Smith \& Haggerty, 2011).

In their systematic review and meta-analysis of 44 studies evaluating the effectiveness of anti-bullying programs in schools, Ttofi and Farrington (2011) found that school-based anti-bullying programs were, on average, $17 \%-20 \%$ effective in reducing students' victimization from bullying. Assuming Ttofi and Farrington's (2011) most conservative 17\% estimate as well as the U.S. Education Department's (2014) most conservative 15\% estimated prevalence of bully victimization in U.S. schools (referred to earlier in Section 3), together with the annual $\$ 130 \overline{M V}_{\text {Victim }}$ estimate in Table 3, the $N B$ per student of an annual $\$ 25-\$ 150$ per student investment in a bullying prevention program for a 500 -student elementary school ranges from $\$ 1508$ to $\$ 1633$ per year with a total $N B$ of $\$ 0.754$ to $\$ 0.8165$ million per year. Holding all parameters constant, parental $\overline{M V}_{\text {Victim }}$ would have to fall below $\$ 11.76$ for the program to be unbeneficial at the annual $\$ 150$ per student cost. Similarly, the program's effectiveness could be as low as $1.54 \%$ and still be beneficial at the $\$ 150$ per student cost. In addition, as evidenced by expression (10), the bullying prevention program's $N B$ falls as the school's student enrollment falls. This is due to the fact that the aggregate marginal value of a public good declines with fewer users of the good. Thus for instance, at current parameter values and a $\$ 150$ per student annual cost, the elementary school needs to have an enrollment of at least 46 students for the bullying prevention program to be net beneficial ( 8 or more students are required at a $\$ 25$ per student cost). There is power in numbers, however. If the question of U.S. representativeness of the sample used in this study is set aside, for the 32.565 million children who attended a U.S. elementary school in 2003, a yearly $\$ 150$ per student investment in school-based bullying prevention yields an annual $N B$ per student $=\$ 107.95$ million with a total annual $N B=\$ 3.5$ billion.

\section{Conclusions}

This paper developed and implemented an approach to assess the ex ante monetary benefits parents attach to reductions in their children's victimization from bullying at school. Though these benefits accrue to the parents alone, they add to the literature cited in Section 1 about the ex post private (e.g., increased adult earnings) and public (e.g., increased adult productivity) benefits the child may ultimately 
realize. Parental benefit measures are derived in the context of a household utility maximization model and reflect a point estimate of parents' conditional marginal rate of substitution between parental income and their disutility of bully victimization. A lower bound estimate of this substitution rate is inferred from parents' discrete choices to change their child's school conditional on their child's bully victimization status and parent, child, and school characteristics. The conditional choice model is estimated using a bivariate probit model and a unique panel of 595 families from the NICHD Study of Early Child Care and Youth Development for 2000 to 2003. Empirical results are consistent with the hypothesis that when children are victims of bullying at school, at least some parents alter their perceptions of school quality and engage in the remedial action of switching their child's school. Sample lower bound estimates of parents' ex ante marginal annual value of reduced child bully victimization average $\$ 130$ and range from $\$ 54$ for parents whose child was not bullied to $\$ 633$ for parents whose child was bullied.

Though the technique used in this paper likely undervalues parents' true willingness to pay for reduced bully victimization, when combined with literature estimates of U.S. bullying prevalence and the cost and effectiveness of currently available anti-bullying programs, in nearly all cases willingness to pay estimates produced positive, and most often substantial, net program benefits. To the extent that victims of bullying incur any additional ex post psychological, wealth, and punitive costs (Wolke et al., 2013), U.S. investments in school-based anti-bullying programs could be welfare improving even at program costs well in excess of the upper range assumed in this paper. Some caveats are worthy of mention. First, while the positive net benefits presented in Section 4 are robust to parental marginal values substantially lower than those reported in Table 3, parameter estimates from qualitative choice models like bivariate probit can be sensitive to the assumed form of the underlying distribution. Second, we ignore possible influences of the attributes of the child's current school upon school change opportunities. Third, all self-reported measures are subject to error and a variety of conscious and unconscious distortions of actual events. While the test-retest reliability of the Kids in My Class at School questionnaire to measure children's victimization from bullying is favorable (Demaray \& Malecki, 2002), the rate of bully victimization measured from this instrument may not accurately reflect the true rate.

\section{References}

Agee, Mark D. \& Crocker, Thomas D. (2007). Children's Health Benefits of Reducing Environmental Tobacco Smoke Exposure: Evidence from Parents Who Smoke. Empirical Economics, 32(1), 217-237. 
Agee, Mark D. \& Crocker, Thomas D. (2011). Child Development when Parents Enjoy Childcare. Journal of Institutional and Theoretical Economics, 167(2), 392-407.

Arseneault, Louise, Walsh, Elizabeth, Trzesniewski, Kali, Newcombe, Rhiannon, Caspi, Avshalom \& Moffitt, Terrie E. (2006). Bullying Victimization Uniquely Contributes to Adjustment Problems in Young Children: A Nationally Representative Cohort Study. Pediatrics, 118(1), 130-138.

Arseneault, Louise, Bowes, Lucy \& Shakoor, Sania (2010). Bullying Victimization in Youths and Mental Health Problems: Much Ado About Nothing? Psychological Medicine, 40(5), 717-729.

Baldry, Anna C. (2004). The Impact of Direct and Indirect Bullying on the Mental and Physical Health of Italian Youngsters. Aggressive Behavior, 30(5), 343-355.

Becker, Gary S. (1965). A Theory of the Allocation of Time. The Economic Journal, 75(299), 493-517.

Bhattacharya, Jay, Goldman, Dana \& McCaffrey, Daniel (2006). Estimating Probit Models with Self-Selected Treatments. Statistics in Medicine, 25(3), 389-413.

Bockstael, Nancy E. \& McConnell, Kenneth E. (1983). Welfare Measurement in the Household Production Framework. The American Economic Review, 73(4), 806-814.

Brown, Eric C., Low, Sabina, Smith, Brian H. \& Haggerty, Kevin P. (2011). Outcomes From a School-Randomized Controlled Trial of Steps to Respect: A Bullying Prevention Program. School Psychology Review, 40(3), 423.

Brown, Sarah \& Taylor, Karl (2008). Bullying, Education and Earnings: Evidence From the National Child Development Study. Economics of Education Review, 27(4), 387-401.

Chernozhukov, Victor \& Hansen, Christian (2008). The Reduced Form: A Simple Approach to Inference with Weak Instruments. Economics Letters, 100(1), 68-71.

Cooke, Michelle Beaulieu, Ford, Julian, Levine, Joan, Bourke, Cate, Newell, Lisa \& Lapidus, Garry (2007). The Effects of City-Wide Implementation of 'Second Step' on Elementary School Students' Prosocial and Aggressive Behaviors. The Journal of Primary Prevention, 28(2), 93-115.

Cook, Clayton R., Williams, Kirk R., Guerra, Nancy G., Kim, Tia E. \& Sadek, Shelly (2010). Predictors of Bullying and Victimization in Childhood and Adolescence: A Meta-Analytic Investigation. School Psychology Quarterly, 25(2), 65.

Demaray, Michelle Kilpatrick \& Malecki, Christine Kerres (2002). The Relationship Between Perceived Social Support and Maladjustment for Students at Risk. Psychology in the Schools, 39(3), 305-316.

Dickie, Mark \& Gerking, Shelby (2007). Altruism and Environmental Risks to Health of Parents and Their Children. Journal of Environmental Economics and Management, 53(3), 323-341.

Diperna, James Clyde \& Volpe, Robert J. (2005). Self-Report on the Social Skills Rating System: Analysis of Reliability and Validity for an Elementary Sample. Psychology in the Schools, 42(4), 345-354.

Doll, Beth, Song, Samuel \& Siemers, Erin (2004). Classroom Ecologies that Support or Discourage Bullying. In D. Espelage, E. Gutgsell \& S. Swearer (Eds.), Bullying in American Schools: A Social-Ecological Perspective on Prevention and Intervention (pp. 161-183). New York: Routledge.

Due, Pernille, Merlo, Juan, Harel-Fisch, Yossi, Trab Damsgaard, Mogens \& Holstein, Bjørn E. (2009). Socioeconomic Inequality in Exposure to Bullying during Adolescence: A Comparative, Cross-Sectional, Multilevel Study in 35 Countries. American Journal of Public Health, 99(5), 907-914. 
Duncan, Renae D. (2011). Family Relationships of Bullies and Victims. In D. Espelage \& S. Swearer (Eds.), Bullying in North American Schools (2nd ed.). (pp. 191-204). New York: Routledge.

Egan, Susan K. \& Perry, David G. (1998). Does Low Self-Regard Invite Victimization? Developmental Psychology, 34(2), 299-309.

Eisenberg, Nancy, Fabes, Richard A. \& Spinrad, Tracy L. (2006). Handbook of Child Psychology: Vol. 3 (6th ed.). Hoboken, NJ: John Wiley \& Sons.

Eriksen, Tine Louise Mundbjerg, Nielsen, Helena Skyt \& Simonsen, Marianne (2014). Bullying in Elementary School. Journal of Human Resources, 49(4), 839-871.

Fanti, Kostas A. \& Georgiou, Stelios N. (2013). Bullying, Victimization, School Performance \& Mother-Child Relationship Quality: Direct and Transactional Associations. Journal of Criminology, 289689; http://dx.doi.org/10.1155/2013./289689.

Fanti, Kostas A., Frick, Paul J. \& Georgiou, Stelios (2009). Linking Callous-Unemotional Traits to Instrumental and Non-Instrumental Forms of Aggression. Journal of Psychopathology and Behavioral Assessment, 31(4), 285-298.

Freeman, A. Myrick, III, Herriges, Joseph A. \& Kling, Catherine L. (2014). The Measurement of Environmental and Resource Values: Theory and Methods. New York: Routledge.

Graham, Sandra (2006). Peer Victimization in School Exploring the Ethnic Context. Current Directions in Psychological Science, 15(6), 317-321.

Gresham, Frank M. \& Elliott, Stephen N. (1990). Social Skills Rating System: Manual. Circle Pines, MN: American Guidance Service.

Hau, Timothy Doe-Kwong (1985). A Hicksian Approach to Cost-Benefit Analysis with Discrete-Choice Models. Economica, 52(208), 479-490.

Hay, Dale F., Payne, Alexandra \& Chadwick, Andrea (2004). Peer Relations in Childhood. Journal of Child Psychology and Psychiatry, 45(1), 84-108.

Heckman, James J. (1978). Dummy Endogenous Variables in a Simultaneous Equation System. Econometrica, 46, 931-959.

Henrich, Christopher C. \& Shahar, Golan (2014). Moderators of the Effect of Peer Victimization during Fifth Grade on Subsequent Symptoms of (Anxious) Depression: The Roles of Engagement in Bullying and Baseline Symptomatology. Prevention Science, 15(6), 888-896.

Holt, Melissa K. \& Keyes, Melissa A. (2004). Teachers' Attitudes toward Bullying. In D. Espelage, E. Gutgsell \& S. Swearer (Eds.), Bullying in American Schools: A SocialEcological Perspective on Prevention and Intervention (pp. 121-139). New York: Routledge.

Johansson, Per-Olov (1991). An Introduction to Modern Welfare Economics. New York: Cambridge University Press.

Jones, Andrew M. (2007). Applied Econometrics for Health Economists: A Practical Guide. Abingdon: Radcliffe.

Kasen, Stephanie, Johnson, Jeffrey G., Chen, Henian, Crawford, Thomas N. \& Cohen, Patricia (2011). School Climate and Change in Personality Disorder Symptom Trajectories Related to Bullying: A Prospective Study. In D. Espelage \& S. Swearer (Eds.), Bullying in North American Schools (2nd ed.). (pp. 161-181). New York: Routledge.

Kochenderfer, Becky J. \& Ladd, Gary W. (1996). Peer Victimization: Cause or Consequence of School Maladjustment? Child Development, 67(4), 1305-1317.

Kochenderfer, Becky J. \& Ladd, Gary W. (1997). Victimized Children's Responses to Peers' Aggression: Behaviors Associated with Reduced Versus Continued Victimization. Development and Psychopathology, 9(1), 59-73. 
Ladd, Gary W., Kochenderfer, Becky J. \& Coleman, Cynthia C. (1997). Classroom Peer Acceptance, Friendship, and Victimization: Distinct Relation Systems that Contribute Uniquely to Children's School Adjustment. Child Development, 68(6), 1181-1197.

Lancaster, Kelvin J. (1966). A New Approach to Consumer Theory. Journal of Political Economy, 74(2), 132-157.

Limber, Susan P. (2011). Development, Evaluation, and Future Directions of the Olweus Bullying Prevention Program. Journal of School Violence, 10(1), 71-87.

Lynch, Kathleen B., Geller, Susan R. \& Schmidt, Melinda G. (2004). Multi-Year Evaluation of the Effectiveness of a Resilience-Based Prevention Program for Young Children. Journal of Primary Prevention, 24(3), 335-353.

Maddala, Gangadharrao S. (1986). Limited-Dependent and Qualitative Variables in Econometrics. Cambridge: Cambridge University Press.

McFadden, Daniel L. (1974). The Measurement of Urban Travel Demand. Journal of Public Economics, 3(4), 303-328.

McFadden, Daniel L. (1976). Quantal Choice Analysis: A Survey. In S. Berg (Ed.), Annals of Economic and Social Measurement (pp. 363-390). National Bureau of Economic Research; http//www.nber.org/chapters/c10488.

McFadden, Daniel L. (1980). Econometric Models for Probabilistic Choice among Products. Journal of Business, 53(3), S13-S29.

Monfardini, Chiara \& Radice, Rosalba (2008). Testing Exogeneity in the Bivariate Probit Model: A Monte Carlo Study. Oxford Bulletin of Economics and Statistics, 70(2), 271-282.

Nansel, Tonja R., Haynie, Denise L. \& Simonsmorton, Bruce G. (2003). The Association of Bullying and Victimization with Middle School Adjustment. Journal of Applied School Psychology, 19(2), 45-61.

NICHD Early Child Care Research Network (2001). Nonmaternal Care and Family Factors in Early Development: An Overview of the NICHD Study of Early Child Care. Journal of Applied Developmental Psychology, 22(5), 457-492.

Olweus, Dan \& Limber, Susan P. (2007). Olweus Bullying Prevention Program: Teacher Guide. Center City, MN: Hazelden.

Olweus Bullying Prevention Program. 2015. http://www.violencepreventionworks.org/publ ic/document/obppsampleprintcost.pdf.

Perkins, Wesley J., Perkins, Jessika \& Craig, David (2009). Where Does Bullying Take Place Among Adolescents When They Are at School? Presented at American Public Health Association Annual Meetings, Philadelphia, PA.

Persson, Mattias \& Svensson, Mikael (2013). The Willingness to Pay to Reduce School Bullying. Economics of Education Review, 35, 1-11.

Pitt, Mark M., Rosenzweig, Mark R. \& Hassan, Md Nazmul (1990). Productivity, Health, and Inequality in the Intrahousehold Distribution of Food in Low-Income Countries. The American Economic Review, 80(5), 1139-1156.

Puhl, Rebecca M., Luedicke, Joerg \& King, Kelly M. (2015). Public Attitudes about Different Types of Anti-Bullying Laws: Results from a National Survey. Journal of Public Health Policy, 36(1), 95-109.

Rose, Chad A., Allison, Stephen \& Simpson, Cynthia G. (2012). Addressing Bullying Among Students with Disabilities within the School Environment. In D. Hollar (Ed.), Handbook of Children with Special Health Care Needs (pp. 383-397). New York: Springer. 
Sarzosa, Miguel \& Urzúa, Sergio (2015). Bullying among adolescents: The role of cognitive and non-cognitive skills. National Bureau of Economic Research Working Paper, W21631.

Scapecchi, Pascale (2005). Valuation Differences between Adults and Children. In Economic Valuation of Environmental Health Risks to Children. Paris: OECD Publishing.

Schwartz, David, Dodge, Kenneth A. \& Coie, John D. (1993). The Emergence of Chronic Peer Victimization in Boys' Play Groups. Child Development, 64(6), 1755-1772.

Short, Paula M. (1988). Effectively Disciplined Schools: Three Themes from Research. NASSP Bulletin, 72(504), 1-3.

Small, Kenneth A. \& Rosen, Harvey S. (1981). Applied Welfare Analysis with Discrete Choice Models. Econometrica, 49(1), 105-130.

Smedley, Stanley R. \& Willower, Donald J. (1981). Principals' Pupil Control Behavior and School Robustness. Educational Administration Quarterly, 17(4), 40-56.

Staiger, Douglas \& Stock, James H. (1997). Instrumental Variables Regression with Weak Instruments. Econometrica, 65(3), 557-586.

Swearer, Susan M., Song, Samuel Y., Cary, Paulette Tam, Eagle, John W. \& Mickelson, William T. (2001). Psychosocial Correlates in Bullying and Victimization: The Relationship between Depression, Anxiety, and Bully/Victim Status. Journal of Emotional Abuse, 2(2-3), 95-121.

Swearer, Susan M., Peugh, James, Espelage, Dorothy L., Siebecker, Amanda B., Kingsbury, Whitney L. \& Bevins, Katherine S. (2006). A Social-Ecological Model for Bullying Prevention and Intervention in Early Adolescence: An Exploratory Examination. In S. Jimerson, S. Swearer \& D. Espelage (Eds.), Handbook of Bullying in Schools: An International Perspective (pp. 61-72). New York: Routledge.

Tirozzi, Gerald N. (2001). The Artistry of Leadership: The Evolving Role of the Secondary School Principal. Phi Delta Kappan, 82(6), 434-439.

Ttofi, Maria M. \& Farrington, David P. (2011). Effectiveness of School-Based Programs to Reduce Bullying: A Systematic and Meta-Analytic Review. Journal of Experimental Criminology, 7(1), 27-56.

U.S. Department of Education. Office of Planning, Evaluation Policy Development, Policy and Program Studies Service (2011). Analysis of State Bullying Laws and Policies. Washington, DC.

U.S. Department of Education, National Center for Education Statistics (2013). Digest of Education Statistics, 2012 (NCES 2014-015). Washington, DC.

U.S. Department of Education, National Center for Education Statistics (2014). Indicators of School Crime and Safety: 2013 (NCES 2014-042). Washington, DC.

U.S. Department of Health and Human Services (2010). Eunice Kennedy Shriver National Institute of Child Health and Human Development. NICHD Study of Early Child Care and Youth Development: Phase III 2000-2004. ICPSR21942-v1. Ann Arbor, MI: Interuniversity Consortium for Political and Social Research [distributor]. doi:10.3886/ICP SR21942.v1.

Wilde, Joachim (2000). Identification of Multiple Equation Probit Models with Endogenous Dummy Regressors. Economics Letters, 69(3), 309-312.

Willig, Robert D. (1976). Consumer's Surplus Without Apology. The American Economic Review, 66(4), 589-597.

Wolke, Dieter, Copeland, William E., Angold, Adrian \& Costello, E. Jane (2013). Impact of Bullying in Childhood on Adult Health, Wealth, Crime, and Social Outcomes. Psychological Science, 24(10), 1958-1970. 